\title{
Enhanced critical current density in MgB2 superconductor via Si and C coadditions.
}

\begin{abstract}
In this study, nanosize Silicon and Carbon $(\mathrm{Si}+\mathrm{C})$ were reacted with $\mathrm{MgB} 2$ in order to enhance the critical current density. The polycrystalline bulks were synthesized by the direct in situ reaction method and their phase formation, crystal structure, and superconducting properties were evaluated. The enhanced relative peak intensity of $\mathrm{Mg} 2 \mathrm{Si}$ and $\mathrm{MgB} 4$ indicates the formation of a large volume fraction of these two phases with increasing $(\mathrm{Si}+\mathrm{C})$ additions. The a-axis lattice parameter shrinks significantly while c-axis increases slightly. The estimated $\mathrm{C}$ doping level at $\mathrm{B}$ site increases, leading to a degradation of the superconducting transition temperature with increasing $(\mathrm{Si}+\mathrm{C})$ additions. By a reaction with $(\mathrm{Si}+\mathrm{C})$, the field dependence of critical current density is shown to enhance at both $5 \mathrm{~K}$ and $20 \mathrm{~K}$.
\end{abstract}

Keyword: MgB2; Carbon doping; Critical current density. 